\title{
Meaningful climate science
}

\section{Theodore G. Shepherd ${ }^{1}$ (D) Elisabeth A. Lloyd ${ }^{2}$ (D)}

Received: 28 October 2020 / Accepted: 14 October 2021

(c) The Author(s) 2021

\begin{abstract}
Within the climate science community, useable climate science has been understood as quantitative, usually as a best estimate together with a quantified uncertainty. Physical scientists are trained to produce numbers and to draw general, abstract conclusions. In general, however, people relate much better to stories and to events they have experienced, which are inevitably contingent and particular. Sheila Jasanoff has argued elsewhere that the process of abstraction in climate science "detaches knowledge from meaning". Perhaps useable climate science is, then, meaningful climate science. We argue here that the development of meaningful climate science can be achieved by adopting a storyline approach to climate variability and change. By 'storyline' we mean a physically selfconsistent unfolding of past events or of plausible future events or pathways. Storylines represent a combination of qualitative and quantitative information, where the qualitative element represents a packaging or contextualization of the quantitative aspects, which ensures that data can be meaningfully interpreted. Viewed from this perspective, we show that physical climate storylines can be aligned with several well-established vehicles for translation of knowledge between diverse communities: narratives, boundary objects, and data journeys. They can therefore be used as a 'pidgin language' to enrich the set of tools available to climate scientists to bring meaning to climate knowledge.
\end{abstract}

"And what is the use of a book", thought Alice, "without pictures or conversations?"

(Lewis Carroll, Alice's Adventures in Wonderland).

Keywords Climate science $\cdot$ Climate change $\cdot$ Storylines $\cdot$ Narratives $\cdot$ Boundary objects · Data journeys

This article is part of the topical collection "Critical and historical perspectives on usable climate science", edited by Deborah R. Coen and Adam H. Sobel

Theodore G. Shepherd

theodore.shepherd@ reading.ac.uk

Elisabeth A. Lloyd

ealloyd@indiana.edu

1 Department of Meteorology, University of Reading, Reading RG6 6BB, UK

2 Department of History and Philosophy of Science and Medicine, Indiana University, Bloomington, IN 47401, USA 


\section{Introduction}

There is a widely acknowledged gap between the production and use of information about climate change (Kirchhoff et al. 2013; Nissan et al. 2019; Hewitt et al. 2020). The gap is apparent in the disconnect between the existential nature of the dangers posed by climate change for human and natural systems (which, without action, will keep getting worse; there is no known self-limiting mechanism) and the general inadequacy of actions being taken both to mitigate the severity of climate change and to adapt to its consequences. There has long been a call for 'useable' (or sometimes 'actionable') climate science in order to overcome the gap (Lubchenco 1998; Meinke et al. 2006; see Coen 2021, this issue, for some historical perspective), yet the gap remains. From the climate science perspective, useable climate science is usually interpreted as quantitative, typically as a best estimate with quantified, probabilistic uncertainties. Much effort goes into the production of information of this type (e.g. IPCC 2018). This is not surprising, since such a format is the generally accepted form of scientific information.

There has been a growing critique of this perspective, from at least two directions. One is that the uncertainties involved in the response of the climate system to anthropogenic forcing are sufficiently deep that they cannot be reliably quantified in a probabilistic way (Dessai and Hulme 2004). The uncertainties are even deeper when one considers the role of the human or natural environment, which is an essential element in the consideration of climate impacts. Representation of uncertainty as an 'error bar' then inevitably leads to wide error bars (Herrando-Pérez et al. 2019). This can convey a lack of knowledge when what scientists are interpreting as an objective measure of uncertainty (reliability, i.e. likely to capture the true value) is interpreted by users as a subjective measure of uncertainty (informativeness, i.e. confidence in the result) (Kahneman and Tversky 1982; Løhre et al. 2019).

A second critique is that science is about abstraction and generalization, and the process of abstraction and generalization, even if it was reliable, detaches knowledge from meaning (Jasanoff 2010). Partly this is because humans generally do not parse probabilistic information very well (Budescu et al. 2012; Sutherland 2013), and partly it is because the process of aggregation over similar but nevertheless distinguishable (and non-exchangeable) entities necessarily removes potentially crucial information about those entities (Cartwright 1999). By creating a gulf between knowledge and meaning, the users of climate information are unable to participate in the quality assessment that is so crucial when system uncertainties are deep and the stakes are high (Funtowicz and Ravetz 1993).

The need to address both critiques has led to the development of so-called 'storyline' approaches to climate information (Shepherd et al. 2018), which prioritize plausibility and self-consistency over probability, and informativeness over reliability. Such approaches have a long pedigree in climate-change science; for example, the landmark Charney report (NRC 1979) employed it out of necessity because at that time there were only two climate models available for analysis. However, as the number of climate models has increased, the probabilistic approach has become normative (e.g. IPCC 2018). Storyline approaches are also the natural perspective in dynamical meteorology and weather science, and the causal factors behind the summer 2003 European heatwave were discussed in detail by Black et al. (2004) from this perspective. Yet the probabilistic approach of Stott et al. (2004) to the same event, which ignored all those factors and targeted a much weaker, coarse-grained 'event' of only $1.6 \mathrm{C}$ above the mean (to avoid selection bias), has now become the dominant approach in extreme event attribution (van 
Oldenborgh et al. 2021), to the extent of being the basis for a prototype operational climate service. ${ }^{1}$

We adopt the (physical climate) storyline definition in Shepherd et al. (2018) of "a physically self-consistent unfolding of past events, or of plausible future events or pathways". Such a deterministic, multivariate representation of climate information stands in stark contrast to traditional probabilistic representations, which are generally univariate and in the form of a best estimate together with a quantified uncertainty. Storylines thus respond to Stirling's (2010) plea to "keep it complex" when the state of knowledge is most accurately represented in a plural conditional rather than a single definitive form. It has been argued that physical climate storylines can provide a way to connect 'global', or general, climate information to 'local', or particular, contexts, and thus to bring meaning to those contexts (Shepherd and Sobel 2020). This is especially important because, as Sobel (2021) has argued, in the current state of knowledge, actionable climate science is adaptation science, which is inherently local.

The potential for physical climate storylines to provide a vehicle for crossing disciplinary or social boundaries, which is essential to meaning-making, is already evident in their story-telling or narrative element. In the words of the historian Hayden White (1980),

...narrative might well be considered a solution to a problem of general human concern, namely, the problem of how to translate knowing into telling, the problem of fashioning human experience into a form assimilable to structures of meaning that are generally human rather than culture-specific. We may not be able fully to comprehend specific thought patterns of another culture, but we have relatively less difficulty understanding a story coming from another culture, however exotic that culture may appear to us. As Barthes ${ }^{2}$ says, "narrative ... is translatable without fundamental damage" in a way that a lyric poem or a philosophical discourse is not.

This suggests that...narrative is a metacode, a human universal on the basis of which transcultural messages about the nature of a shared reality can be transmitted. Arising, as Barthes says, between our experience of the world and our efforts to describe that experience in language, narrative "ceaselessly substitutes meaning for the straightforward copy of the events recounted".

Here we draw inspiration from White's (and Barthes') insight and examine the extent to which physical climate storylines can be aligned with narratives and other recognized vehicles for translation of knowledge between diverse communities, drawing on literature from the social sciences and humanities. Note that our focus here is on storylines as a form of climate information, to allow transdisciplinary, two-way translation of knowledge, rather than on how pre-existing climate information is communicated, which is a one-way process of translation and is itself the subject of a large literature (Corner et al. 2018). Moreover, although storylines are certainly relevant to co-development and co-production of climate information, the existence of identifiable partners introduces many other elements such as power relationships (Harvey et al. 2019), which deserve their own treatment. Thus, returning to the quotation from Hayden White, we are particularly interested here in situations where those who will engage with climate information are unknown and may do so in the future. In other words, we focus here on how climate information can be packaged for

\footnotetext{
${ }^{1} \mathrm{https}: / /$ climate.copernicus.eu/prototype-extreme-events-and-attribution-service

2 The reference is to Barthes R (1966) Introduction à l'analyse structurale des récits. Communications No. 8 .
} 

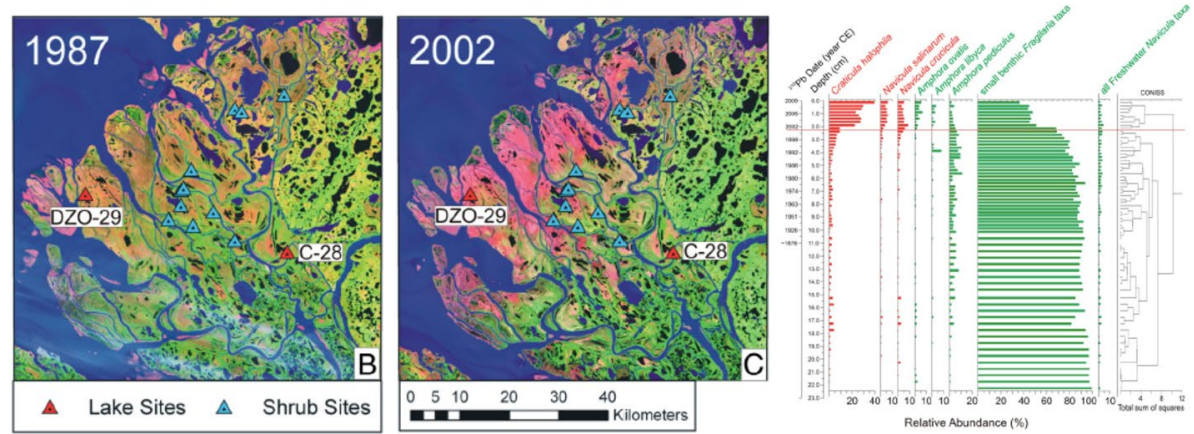

Fig. 1 Collapse of an Arctic ecosystem in the Mackenzie Delta in northern Canada from a storm surge inundation in 1999. The two leftmost panels show LANDSAT images from space before and after the event, where green colours indicate freshwater species and red colours brackish species. The rightmost panel shows stratographic profiles from lake sediments at the site labelled DZO-29, going back 400 years, with again green and red indicating freshwater and brackish species, respectively. From Pisaric et al. (2011)

travel. Our target audience is climate scientists with interdisciplinary interests and those working in the space between climate science and society. Our goal is to enrich the set of tools available to climate scientists for crossing disciplinary boundaries and thereby bringing meaning to climate knowledge. It is decidedly not to shed any new light on the interdisciplinary concepts we discuss, which are themselves the subject of considerable literature. A more nuanced unpacking of those concepts in the context of climate science would no doubt be possible, but our necessarily simplified treatment is sufficient to serve our purposes here.

We start in Sect. 2 by making the concept of a physical climate storyline concrete, with a 'case report' of the collapse of an Arctic ecosystem from a storm surge event. This example then serves as a point of reference for the subsequent analysis. In Sect. 3 we discuss the use of narrative within science-again, as a way of doing science, rather than merely communicating it—which is particularly well established in evolution and ecology. Section 4 then moves to narrative more generally, including future narratives. We discuss Star and Griesemer's (1989) concept of 'boundary objects' in Sect. 5 and Leonelli's (2016) concept of 'data journeys' in Sect. 6; both address the explicit goal of packaging scientific information for flexible use, so are particularly relevant for climate information. The paper concludes with a Discussion, where we return to the challenge of useable climate science.

\section{A storyline of Arctic ecosystem collapse}

We make the concept of a physical climate storyline concrete through the example of an extreme event, namely, the collapse of an Arctic ecosystem from a storm surge. Briefly, a freshwater ecosystem in the Mackenzie Delta in northern Canada was inundated with saltwater during a storm surge in 1999 (Pisaric et al. 2011). The satellite images (Fig. 1) show the widespread collapse of the ecosystem and its replacement by brackish species, an event the palaeoclimate data from lake sediments show was unprecedented in the historical record of over 1000 years (this was supported by another sample not shown in Fig. 1), which appeared to be irreversible. In their account of the event, Pisaric et al. (2011) discuss a number of potential causal factors, which are represented in Fig. 2. [Pisaric et al.'s 


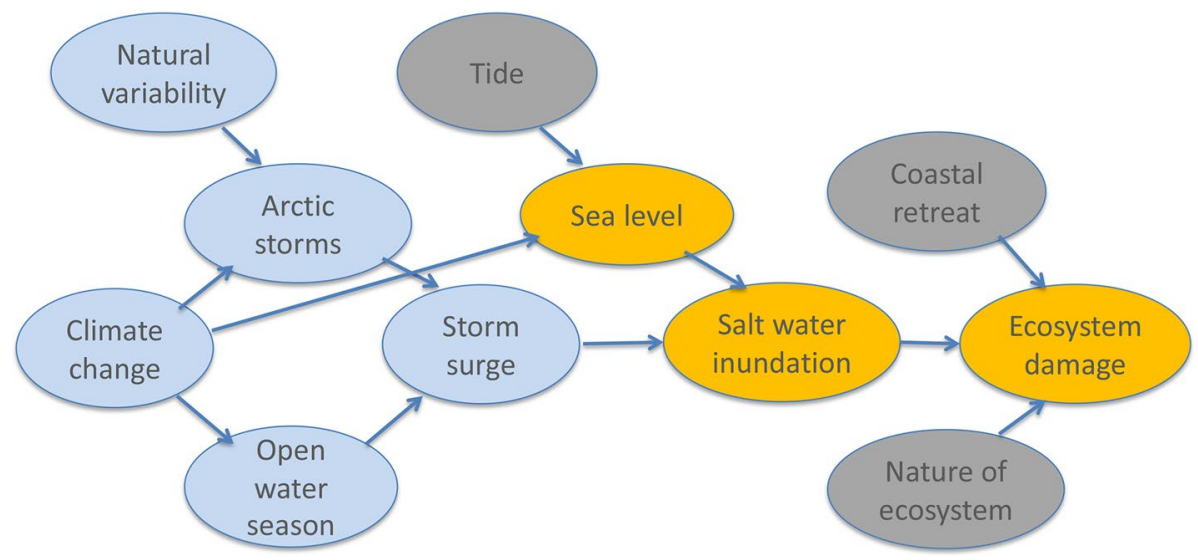

Fig. 2 Causal network representing the extreme event in Fig. 1. The blue shading indicates elements whose causality lies in the weather and climate domain, the grey shading indicates those in the environment and ecosystems domain, and the orange shading indicates a combination of the two. Arrows indicate the direction of causal influence. From Lloyd and Shepherd (2020)

analysis of the event is discussed in more detail from the storyline perspective in Lloyd and Shepherd (2020).]

The proximate cause of the saltwater inundation was the storm surge, which was linked to the longer open-water season in the Arctic because of the loss of sea ice from climate change (Overeem et al. 2011). This would have been exacerbated by rising sea level, also from climate change. A storm was of course necessary, and while storminess might have been affected by climate change, such a hypothesis is subject to considerable scientific uncertainty. Thus the storm can also be regarded as a chance event, from natural variability. Coastal retreat is a widespread consequence of rising sea level and could have been a contributing factor but was ruled out in this particular case because of the details of the local situation. Similarly, the possible role of a high tide was excluded. The nature of the ecosystem was of course crucial: the freshwater ecosystem was vulnerable to saltwater inundation, but a further such event would not have the same consequences, as the ecosystem changed irreversibly.

The description just given is a physical climate storyline in the sense used here, namely, a physically self-consistent unfolding of a past event, described in terms of causal elements. The description is not in any way probabilistic, nor did Pisaric et al. (2011) conduct any probabilistic analysis (e.g. in terms of return periods); their focus was on demonstrating that the event was unprecedented in the 1000-year-long historical record and was apparently irreversible. Thus, it was treated as a singular event, with many of the causal factors regarded as contingent. Such a forensic approach to event attribution, which exemplifies the storyline approach, is prevalent in the ecological literature (Lloyd and Shepherd 2020).

\section{Narrative in science}

The importance of narrative in science has been a growing theme in recent years, so it is important to discuss this literature before moving on to narrative more generally. For the purpose of this particular discussion we can adopt the definition of Rosales (2017): 


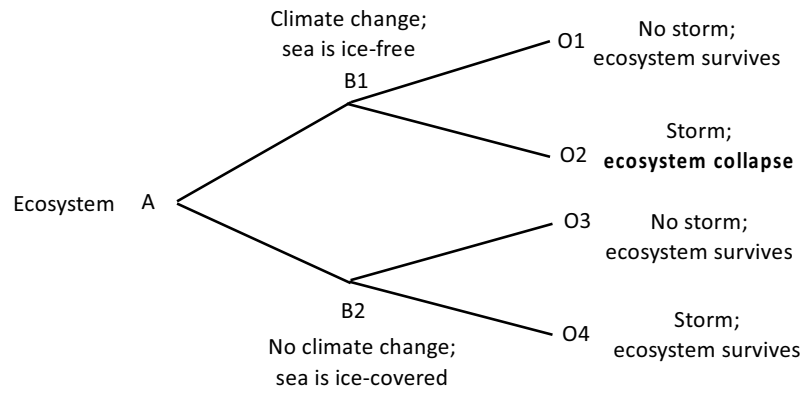

Fig. 3 Branching diagram for the example of Arctic ecosystem collapse depicted in Fig. 1. The system's historical freshwater state is denoted by A. Two other elements from the causal network in Fig. 2 are represented: climate change and Arctic storms. The first moves the system into state B1 rather than state B2. The latter moves the system into either state $\mathrm{O} 2$ or $\mathrm{O} 4$, rather than state $\mathrm{O} 1$ or $\mathrm{O} 3$, depending on whether it is in state $\mathrm{B} 1$ or B2, respectively

"Narratives represent complex processes unfolding in time as a sequence of stages...[and] allow scientists to put together multiple causal influences in a single representation of a process". Such a description, which clearly applies to the example in Sect. 2, is perhaps most readily aligned with natural history and evolution. Indeed, Gould (2002, p.1333) argued:

Natural historians have too often been apologetic, but most emphatically should not be in supporting a plurality of legitimately scientific modes, including a narrative or historical style that explicitly links the explanation of outcomes not only to spatiotemporally invariant laws of nature, but also, if not primarily, to the specific contingencies of antecedent states, which, if constituted differently, could not have generated the observed result.

The concept of causality is implicit here in the 'what-if-things-had-been-different' question that is answered by the explanation of outcomes (Woodward 2003, p.221). This is what makes a narrative different from a mere chronicle of what occurred. Beatty (2017) argues that the embedding of narratives within such a counterfactual framing is what makes them causal. He illustrates this through branching diagrams, where future-determining outcomes occur in hinge points. These branching diagrams (which in decision theory are called 'decision trees', and have been applied to adaptive strategies for climate change (Lempert et al. 1996)) are readily aligned with the sort of causal network structure depicted in Fig. 2. Indeed, Fig. 3 depicts a branching diagram for the Arctic ecosystem example, focusing on the starting point (nature of ecosystem) and the hinge points (climate change and Arctic storms) and omitting both the mediating influences (open water season, storm surge, and saltwater inundation) and the incidental or irrelevant ones (tide, sea level, and coastal retreat).

Scientific narratives are essentially scientific hypotheses. However, the contingent nature of narrative explanations means that such hypotheses are not testable in the traditional scientific manner, through repeated experimentation, as can be done with spatiotemporally invariant laws of nature. For this reason narratives can all too easily be 'just-so' stories (Otto and Rosales 2020). Indeed, Gould had earlier warned "Often, evolutionists use consistency with natural selection as the sole criterion and consider their work done when they concoct a plausible story. But plausible stories can always be told." (Gould 
and Lewontin 1979, p.288, emphasis added). The remedy here is to also consider alternative explanations. To quote Jeffreys (1961, p.58): "We get no evidence for a hypothesis by merely working out its consequences and showing that they agree with some observations, because it may happen that a wide range of other hypotheses would agree with those observations equally well. To get evidence for it we must also examine its various contradictories and show that they do not fit the observations". A sophisticated defence of narrative explanations from philosophy of science comes from Griesemer (1996, p.19), who points out: "The historical sciences derive their distinctive characteristic form not from the intrinsic nature of their subject matter, nor from pure narrative, but from theoretical coordination of both mechanism and narrative... first... identify the respectable theoretical activity associated with narrative construction and then... argue that this activity is not inimical to good mechanistic modeling and explanation."

Otto and Rosales (2020) argue that in ecology and evolution, mathematical models are framed and interpreted within a narrative and that scientific debates tend to arise from the narratives rather than from the mathematics. They support their argument with a number of examples from ecology and evolution, but their insight clearly applies to any study of open systems where controlled experiments are not possible. In short, it applies to the natural world, including climate science, which is governed by an uneven patchwork of laws (Cartwright 1999). The notion that narratives provide the background knowledge within which observations can be interpreted through a mathematical model is very Bayesian (Shepherd 2021). Just as data does not 'speak for itself', neither do mathematical models speak for themselves (Otto and Rosales 2020). Narrative is inevitable in science, whether or not it is made explicit.

The essential distinction between contingent, particular explanations and spatiotemporally invariant laws of nature is highlighted by Forrester (1996), who asks whether there can be such a thing as a science of the individual case. This is reflected in his distinction between prototypes (single cases as exemplars of general principles) and categories (classes of events, or 'populations' to use the language of frequentist statistics). Storylines take the first of these two paths, and probabilistic approaches the second. Consistent with the first path, philosopher of science David Hull (1975, p.274) took an idiosyncratic approach very different from the logical positivist view (which is similar to today's probabilistic approach) dominant at the time:

In historical narratives, an event is not explained by subsuming it under a generalization [as the logical positivists demand]. Instead it is explained by integrating it into an organized whole. . . The logic of the part-whole relation has been worked out in great detail. All that remains is for someone to set out the logical structure of integrative explanations.

\section{Climate storylines as narratives}

The fact that narratives (now understood more generally, in the sense used in the earlier quotation from Hayden White) can convey meaning and survive translation between cultures suggests they can be an effective vehicle for crossing disciplinary or epistemological boundaries. It is not surprising that physical climate storylines can be considered as narratives; indeed sometimes the terms storylines and narratives are used interchangeably (Shepherd et al. 2018). We start by referring to the cognitive psychologist Jerome Bruner's discussion of the four elements that in his view constitute a narrative (Bruner 1990, 
p.77) - agentivity; sequential order; violation of canonicality; and a narrator's perspective, or voice-and identify them in the Arctic ecosystem example discussed in Sect. 2.

Bruner defines 'agentivity' as "action directed toward goals controlled by agents". However, such a requirement of intentional action, which implies an animate and conscious agent, seems unnecessarily restrictive, and we follow Cruse (1973) in allowing agents to be inanimate. Cruse's example of an inanimate agent is the wind, which is entirely à propos; the novelist Amitav Ghosh (2016) has recently argued that in order to think about climate change, we need to recognize its narrative agentivity. The important thing is that the agent can be regarded as a causal factor in the narrative. The causal network shown in Fig. 2 thus provides a way of constructing a narrative of the event, where the agentivity is that from climate change acting together with a natural but chance event (the Arctic storm). For most extreme events there will also be agentivity in the local factors, but not so much in this case (coastal retreat and the nature of the ecosystem), as the ecosystem is not a managed one.

Bruner's requirement of 'sequential order' is clear from the way the observed record of the event is represented in Fig. 1, as well as from the branching diagram in Fig. 3. Bruner's 'voice' is the ecosystem perspective, evocatively portrayed in the images in Fig. 1. And Bruner's 'violation of canonicality' is something out of the ordinary, or 'uncanny' (Ghosh 2016). A scientist would call it detecting signal from noise or statistical significance. An event with no precedent in the 1000-year-long historical record is certainly such an event. As Bruner (1990, p.47) states, narratives are "purpose-built for rendering the exceptional and the unusual into comprehensible form".

Bruner (1990, p.44) also notes that a narrative "can be 'real' or 'imaginary' without loss of its power as a story". That is a crucial concept for climate information, since the effect of climate change is understood as the difference between the real, factual world with climate change and an imaginary counterfactual world without climate change (see Fig. 3). That storylines can seamlessly connect the real and imaginary world is part of their power. Agentivity can be aligned with counterfactual thinking, since outcomes could have been different had the agentivity been different or expressed itself in different ways (see the displayed quotation from Gould in Sect. 3).

The concept of an imaginary world applies not only to a counterfactual unrealized past, but also, quite obviously, to possible futures. Hyvärinen (2016) suggests that Bruner's definition of narrative is overly restrictive when it comes to narratives of the future, which may be more akin to painting a picture of a future world, without a temporal sequence and with no violations of canonicality within the narrative. He puts it thus: "Perhaps it would not be too far-fetched to talk about the domestication of the future". (20) In this case it is, rather, the entire narrative that violates canonicality with respect to the present.

Narratives of the future are referred to as 'scenarios' in climate science and underpin the Intergovernmental Panel on Climate Change (IPCC) assessments. To be credible they must be plausible. The question is, who defines what is plausible? The established approach in the IPCC is the expert group consensus or 'intuitive logics' approach (Rounsevell and Metzger 2010), which has its origins in military and corporate strategy. However, this approach has been criticized as being prone to groupthink (Lloyd and Schweizer 2014). It also tends to become disconnected from the agentivity that climate assessments are intended to inform-again, detaching knowledge from meaning. Thus, in environmental science more generally, most notably in the Intergovernmental Science-Policy Platform on Biodiversity and Ecosystem Services (IPBES), there is a growing movement towards more bottom-up approaches to scenario development based on positive visions for the relationship between humanity and nature. 
For example, Bennett et al. (2016) propose developing scenarios that build on current examples of good practice, what they call 'Seeds of a good Anthropocene'. Such scenarios can be inspiring whilst still being grounded in reality. What they may lack in terms of overall self-consistency, compared to intuitive logics, is made up for by their more direct relation to agentivity. In that respect, they hew much more closely to Bruner's concept of narrative than do the top-down, consensus-based scenarios, and can be more readily aligned with counterfactual thinking as represented in causal networks such as Fig. 2. Making the agentivity explicit allows the role of imagination to be structured around values and to explore what happens when one value (e.g. climate action, social equity, biodiversity) dominates over the others (Wyborn et al. 2020).

Another criticism of consensus-based scenarios is that they are insufficiently dynamic and overly linear, based on extrapolating current trends. Merrie et al. (2018) propose the use of 'science fiction prototyping' to overcome this rigidity, applied to ocean futures. Science fiction prototypes are "short works of fiction, grounded in scientific fact and crafted for the purpose of starting a conversation about the implications, effects, or ramifications of technology and the future" (Burnam-Fink 2015, p.49). The narrative development involves inflection points, both human and natural, which correspond to the hinge points discussed in Sect. 3 and allow both contingency and agentivity to enter in a dynamic manner.

\section{Climate storylines as boundary objects}

Sociologist Susan Leigh Star and philosopher James Griesemer (Star and Griesemer 1989) introduced the notion of 'boundary objects' into the literature of how science works, specifically in understanding how different branches of the scientific community (in their terms, different 'social worlds') communicate with each other in cooperative projects that involve multiple disciplines. The attribution of climate change to extreme events and the resulting requirements for mitigation, adaptation, and litigation are examples of such cooperative projects involving different social worlds (Burger et al. 2020; Lloyd and Shepherd 2020, 2021).

The notion of the boundary object is meant to answer part of the problem of "common representation in diverse intersecting social worlds". (388) Star and Griesemer begin by noting that "consensus is not necessary for cooperation nor for the successful conduct of work". (388) Boundary objects are an

analytic concept of those scientific objects which both inhabit several intersecting social worlds... and satisfy the informational requirements of each of them. Boundary objects are objects which are both plastic enough to adapt to local needs and the constraints of the several parties employing them, yet robust enough to maintain a common identity across sites... These objects may be abstract or concrete. They have different meanings in different social worlds but their structure is common enough to more than one world to make them recognizable, a means of translation. The creation and management of boundary objects is a key process in developing and maintaining coherence across intersecting social worlds.

As Star and Griesemer suggest, when the worlds of the various workers involved in knowledge production come into contact, a difficulty arises: "The creation of new scientific knowledge depends on communication as well as on creating new findings... 
But because these new objects and methods mean different things in different worlds [disciplines], actors are faced with the task of reconciling these meanings if they wish to cooperate...Scientists and other actors contributing to science translate, negotiate, debate, triangulate and simplify in order to work together". (388-389)

Unpacking this idea, we can see how physical climate storylines serve as boundary objects. In the Arctic ecosystem example discussed in Sect. 2, storylines provide a bridge between the conditional, forensic approach to scientific evidence that is normative in the ecosystem community (Lloyd and Shepherd 2020), and the statistical approach that is normative in the climate science community (Shepherd 2019). This bridge is exemplified by the ability to map back and forth between branching diagrams and causal networks, respectively (see Sect. 3). In particular, for Pisaric et al. (2011), the focus of the data analysis was on the singularity of the event relative to the palaeoclimate record, rather than its statistical significance or representativeness within the wider context of climate change. On the other hand, this wider context (e.g. from IPCC assessment reports) can be brought into the picture for the causal interpretation, e.g. the observed lengthening of the open-water season in the coastal Arctic, which is an accepted consequence of climate change, being a necessary condition for a storm to lead to a storm surge. Pisaric et al. (2011) also refer to traditional knowledge of local indigenous people which suggests an increase in storm surges along this Arctic coastline. This, too, can be readily incorporated, and made sense of, within a storyline context. Each of these points illustrates how storylines can serve as boundary objects between different knowledge communities. Further discussion along these lines is provided in Sect. 7.

As Star and Griesemer note, the intersections of diverse scientific communities and norms "place particular demands on representations... [because they have] to satisfy more than one set of concerns". (412) These problems posed by conflicting views can be managed "via the use of versatile, plastic, reconfigurable...objects that each world can mould to its purposes locally", a description which applies well to climate storylines. For example, Pisaric et al. (2011) mention both sea-level rise and an increase in storminess as consequences of climate change that are relevant to events like the one they describe. However, our own analysis of their study suggests that sea-level rise was not particularly relevant in this case, and we regard the claim of increasing Arctic storminess from climate change to be contestable. However, we can reconfigure their storyline into a simpler one that we are willing to defend, without re-doing the analysis. This illustrates the plasticity of storylines.

In addition, Star and Griesemer emphasize that "each participating world can abstract or simplify the [boundary] object to suit its demands; that is, 'extraneous' properties can be deleted or ignored". (412) The causal networks that underlie storylines are similarly adjustable to different perspectives and interests, by expanding or simplifying particular aspects of the network. For example, Young et al. (2021) applied a storyline approach to quantify climate effects on food security and household economy at a very local scale in a particular region of Namibia. Simplifying the regional climate information by making it contingent rather than predictive allowed the description of the impact on livelihoods to be expanded and deepened using local, trusted knowledge, leading to a meaningful quantification in terms of household income and per-person calorie intake, stratified by wealth group.

In any case, "navigating in more than one world is a non-trivial mapping exercise". Epistemic objects such as storylines ultimately form "a common boundary between worlds by inhabiting them both simultaneously". (413) The production and distribution of storylines in the social, physical, scientific and public contexts can arise from agreements about methods, through which distinct disciplines "establish protocols which go beyond mere trading across unjoined world boundaries. They begin to devise a common coin 
which makes possible new kinds of joint endeavour". (413) In this way, storylines can be thought of as boundary objects for the practice of useable and meaningful applications of climate knowledge.

\section{Climate storylines as data journeys}

Philosopher Sabina Leonelli (2016) has proposed a framework for understanding how data, especially 'big data', are used in pathways between disciplines, administrative contexts, and users. Leonelli describes 'data-centric sciences' as those that prioritize the production and dissemination of data in order to enhance data's evidentiary value. This evidentiary value is enormously augmented by 'data journeys', which are "the material, social, and institutional circumstances by which data are packaged and transported across research situations, so as to function as evidence for a variety of knowledge claims". (5) Such reuse of the data in a different setting involves a process of de-contextualization followed by a re-contextualization, for which she emphasizes the "key roles played by embodied and theoretical knowledge in making data reusable across research contexts" (196). This relates back to Otto and Rosales's (2020) argument about the role of narrative in contextualizing mathematical models and observations (see Sect. 3).

Leonelli studies this added value in the biological field of model organism research, where model organisms (e.g. fruit flies or mice) are used to study a wide range of biological phenomena, not for their own sake but because of their implications for humans. We find that her framework is useful in any science that uses a great deal of data; one of us (Lloyd et al. 2021b) has applied it to climate modelling and its related activities in attribution. Leonelli traces the paths that data 'travel' from their site of production to many realworld and scientific applications (see, e.g., Howlett and Morgan 2011; Leonelli 2016). This is highly topical in the context of climate science, with the increasing focus on data portals intended to serve a diverse and partly unknown community (Leonelli and Tempini 2020). In the Arctic ecosystem example considered in Sect. 2, climate modelling data, climate measurement data, and ecological data are all involved in evidencing the causal chain from climate change to the storm surge and the subsequent ecological changes, despite being produced in different ways and according to different standards. Yet those data are able to 'travel' across disciplinary boundaries (e.g. between consensus climate science as represented in the IPCC reports and palaeoclimate field data) to provide the overall storyline of the event. It is the storyline framework that allows the very different sources of data, with their various strengths and limitations, to consolidate and thus be able to offer the narrative of the event described in Sect. 2.

This concept of data 'travel' actually acquires a mathematical expression in causal networks such as that in Fig. 2. That is because causal networks are built on a Bayesian probability structure, where new information on any network element has immediate implications for other network elements, with the information flow occurring both upstream and downstream with respect to the direction of causal influence (Lindley 2014). For example, whilst the open water was a precondition for a storm surge in our Arctic ecosystem example, the saltwater inundation implied open water. In this way, Leonelli's concept of 'travel' can take on a mathematical meaning of information transfer. It is precisely the conditional (or contingent) representation of the data provided by its storyline that allows the packaging of the data and its subsequent travel, through the logic of causal reasoning (Shepherd 2019). Importantly, Bayesian networks allow the inclusion of any data whatsoever, 
qualitative or quantitative, so long as it can be represented categorically. They thus provide a way to combine traditional and quantitative climate information within an overarching narrative.

An important part of Leonelli's view involves data 'packaging' in preparation for its travel across disciplines and contexts. The ecosystem data displayed in Fig. 1 are not merely images of ecosystem change, such as a photograph of a wildfire; they are data, which are packaged in terms of system state and chronology, ready for travel. The incorporation of field data as a documentation of the event in a tangible way, and its journey into an object of climate significance - thereby making climate change 'visible' (Rudiak-Gould 2013) — is thus made possible by the storyline. Similarly, emphasizing the role of climate modelling evidence in establishing the anthropogenic nature of Arctic sea ice melt helps package the modelling data for informative, greater travel outside the modelling community to this ecological case study, or to other biological or social contexts of application. For example, Pisaric et al. (2011) discuss the implications of the event they study for other Arctic coastal communities, for which the particularities of the situation may be different but the same causal agents are relevant. The success of the modelling and attribution databases has both social and epistemic consequences, as they become standard tools for applications to ecological contexts, easing this journey between climate model and the scientific locale of ecological catastrophe (see Lloyd and Shepherd 2020; Lloyd et al. 2021b). Particular kinds of climate data, such as that from regional climate models, may become preferred in the study of ecological catastrophes and add value to the storylines they appear in as evidence (Lloyd et al. 2021a).

\section{Discussion}

We motivated this article by the striking gap between the production and use of climate information, and argued that part of the problem lies in the way that climate information is generally produced, which detaches knowledge from meaning (Jasanoff 2010). Thus our focus here has been on demonstrating how physical climate storylines can reattach meaning to climate information. Yet this is only part of the problem. Along with the criticism of probabilistic and generalized approaches to knowledge production discussed in the Introduction, there has been a growing criticism of the implicit assumption that the impediment to action is insufficient knowledge, and a recognition that what is needed is a better relationship between scientists and publics (Cook and Overpeck 2019; Coen 2021). For example, a new portal for community science (including a journal that will publish case studies) has recently been launched (Fiser et al. 2021). More generally, Kopp (2021) argues that making (climate) science useable requires "a more robust relationship between scientific research and on-the-ground action, strong networks sharing local lessons globally, and channels for injecting global, long-term perspectives into the noise of short-termism". (He also argues that the US land-grant universities, at their best, provide a potential model for this.) Our premise is that more meaningful ways of representing climate information can help facilitate these goals, by opening the door to transdisciplinary, two-way translation of knowledge.

It is beyond the scope of this article to address the useability question directly, but we give a few examples of how some of the features of storyline approaches have been effective in bridging between scientists and publics (i.e. not just other academics) in the North American Arctic. Bronen et al. (2020) emphasize the importance of engaging indigenous 
knowledge-holders in the design of information systems to monitor and assess environmental change, e.g. in identifying the most relevant causal factors for an impactful storm surge (which draws on lifelong experiences of residents), so as to accurately capture a particular community's vulnerability. Bennett and Lantz (2014) illustrate, for the Mackenzie Delta, how participatory photomapping can document, contextualize, and share indigenous observations of environmental conditions. Buzard et al. (2021) develop narrative-based indigenous-sourced methods for assessing severity of coastal flooding events for various locations in Alaska, using written histories from the community members and objects in the communities to infer flood heights and thereby fill gaps in the instrumental record of flooding for specific locations. These examples illustrate the incorporation of indigenous knowledge within a wider knowledge base, and the use of imagery for story-telling, both of which we have touched on in our earlier discussion.

To summarize, the challenge of producing useable climate science involves the crossing of disciplinary boundaries and social groups, each with their own ways of meaning-making. The challenge becomes particularly acute when the users of climate information are not even known, so that customized tailoring (as goes on in the process of co-development) is not possible. This is where the concepts of narratives, boundary objects, and data journeys become especially powerful. Yet the concepts are clearly also relevant within welldefined use cases, where there are still very significant challenges in the construction of useable climate science.

Narratives are a means of sense-making which is translatable between different cultures. Boundary objects are a means of communication across disciplinary boundaries or between different social groups. Data journeys (following appropriate packaging of the data) are a means of allowing data to travel outside their immediate disciplinary context. Climate storylines encapsulate all three concepts, as we have demonstrated in our discussion above. The philosopher of science Thomas Kuhn (2012) emphasized the importance of 'pidgin languages' for effective interdisciplinary collaboration. (Kuhn was discussing the collaboration between different scientific disciplines, but the point is clearly more general, and we intend the term in a broader sense here.) Pidgin languages are simplified representations of more complex concepts which will have different meanings in different disciplines, but any simplified language still needs to be precise enough to avoid misunderstanding and serve as an effective communication device. As such, pidgin includes a rich gestural vocabulary complementing any spoken words, just as scientific communication incorporates visual representations such as figures, charts, or videos to enrich and convey meaning. We would thus argue that physical climate storylines, in their various guises, can serve as a pidgin language in the dialogue between climate scientists and the wider society.

Importantly, climate storylines are not simply stories; for example, the underlying causal network structure (as in Fig. 2) is what allows the consideration of alternative explanations and plausible counterfactuals (which is needed to avoid over-confidence in any particular explanation) and the data journeys. They thus provide an important vehicle for the construction of meaningful, and thereby useable, climate information-what Geertz (1973) called a 'thick description', prioritizing depth and particularity over breadth and generality, where "theory is used ... to ferret out the unapparent import of things" (320)—crossing between social- and physical-science applications, creating pictures, and bringing all participants into the conversation.

Acknowledgements The comments of the reviewers and the Editor, as well as those of Jim Griesemer, are appreciated for helping to improve the clarity of the article. 
Authors' contributions Both authors jointly conceived and wrote the piece.

Funding TGS acknowledges EU H2020 RECEIPT \#820712. EAL acknowledges NSF SES \#1754740.

Data availability Not applicable.

Code availability Not applicable.

\section{Declarations}

Ethical approval Not applicable.

Consent to participate Not applicable.

Consent to publish Not applicable.

Conflict of interest The authors declare no competing interests.

Open Access This article is licensed under a Creative Commons Attribution 4.0 International License, which permits use, sharing, adaptation, distribution and reproduction in any medium or format, as long as you give appropriate credit to the original author(s) and the source, provide a link to the Creative Commons licence, and indicate if changes were made. The images or other third party material in this article are included in the article's Creative Commons licence, unless indicated otherwise in a credit line to the material. If material is not included in the article's Creative Commons licence and your intended use is not permitted by statutory regulation or exceeds the permitted use, you will need to obtain permission directly from the copyright holder. To view a copy of this licence, visit http://creativecommons.org/licenses/by/4.0/.

\section{References}

Beatty J (2017) Narrative possibility and narrative explanation. Stud Hist Phil Sci 62:31-41

Bennett EM, Solan M, Biggs R, McPhearson T, Norström AV, Olsson P, Pereira L, Peterson GD, Raudsepp-Hearne C, Biermann F, Carpenter SR, Ellis EC, Hichert T, Galaz V, Lahsen M, Milkoreit M, López BM, Nicholas KA, Preiser R, Vince G, Vervoort JM, Xu J (2016) Bright spots: seeds of a good Anthropocene. Front Ecol Environ 14:441-448

Bennett TD, Lantz TC (2014) Participatory photomapping: a method for documenting, contextualizing, and sharing indigenous observations of environmental conditions. Polar Geog 37:28-47

Black E, Blackburn M, Harrison G, Hoskins B, Methven J (2004) Factors contributing to the summer 2003 European heatwave. Weather 59:217-223

Bronen R, Pollock D, Overbeck J, Stevens D, Natali S, Maio C (2020) Usteq: integrating indigenous knowledge and social and physical sciences to coproduce knowledge and support community-based adaptation. Polar Geog 43:188-205

Bruner J (1990) Acts of Meaning. Harvard University Press

Budescu DV, Por H-H, Broomell SP (2012) Effective communication of uncertainty in the IPCC Reports. Clim Chang 11:181-200

Burger M, Wentz J, Horton R (2020) The law and science of climate change attribution. Columbia J Environ Law 45: https://doi.org/10.7916/cjel.v45i1.4730

Burnam-Fink M (2015) Creating narrative scenarios: Science fiction prototyping at Emerge. Futures 70:48-55

Buzard RM, Overbeck JR, Chriest J, Endres KL, Plumb EW (2021) Coastal flood impact assessments for Alaska communities: Alaska Division of Geological \& Geophysical Surveys Report of Investigation 2021-1, 16 pp, https://doi.org/10.14509/30573

Cartwright N (1999) The Dappled World: A Study of the Boundaries of Science. Cambridge University Press.

Coen DR (2021) A brief history of usable climate science. Clim Chang 167:51. https://doi.org/10.1007/ s10584-021-03181-2 
Cook BR, Overpeck JT (2019) Relationship-building between climate scientists and publics as an alternative to information transfer. WIREs Clim Chang 10:e570

Corner A, Shaw C, Clarke J (2018) Principles for effective communication and public engagement on climate change: A Handbook for IPCC authors. Climate Outreach, Oxford

Cruse DA (1973) Some thoughts on agentivity. J. Linguistics 9:11-23

Dessai S, Hulme M (2004) Does climate adaptation policy need probabilities? Clim Policy 4:107-128

Fiser RW, Giampoala M, Hanson B, Pandya R (2021) Society partners to launch a portal for community science. AGU From the Prow. https://fromtheprow.agu.org/society-partners-to-launch-a-portal-forcommunity-science/. Accessed 14 Sept 2021

Forrester J (1996) If p, then what? Thinking in cases. Hist Human Sci 9(3):1-25

Funtowicz SO, Ravetz JR (1993) Science for the post-normal age. Futures 25:739-755

Geertz C (1973) Thick description: toward an interpretive theory of culture. In The Interpretation of Cultures, pp. 310-323. Basic Books.

Ghosh A (2016) The Great Derangement. University of Chicago Press

Gould SJ (2002) The Structure of Evolutionary Theory. Harvard University Press

Gould SJ, Lewontin RC (1979) The spandrels of San Marco and the Panglossian paradigm: a critique of the adaptationist programme. Proc Roy Soc B 205:581-598

Griesemer JR (1996) Periodization and models in historical biology. In: Ghiselin MT, Pinna G (eds) New perspectives on the history of life, vol 20. Memoirs of the California Academy of Sciences, pp 19-30. https://wp.me/a2ukGW-6P. Accessed 1 Oct 2021

Harvey B, Cochrane L, Van Epp M (2019) Charting knowledge co-production pathways in climate and development. Environ Policy Gov 29:107-117

Herrando-Pérez S, Bradshaw CJA, Lewandowsky S, Vieites DR (2019) Statistical language backs conservatism in climate-change assessments. Bioscience 69:209-219

Hewitt CD, Allis E, Mason SJ, Muth M, Pulwarty R, Shumake-Guillemot J, Bucher A, Brunet M, Fischer AM, Hama AM, Kolli RK, Lucio F, Ndiaye O, Tapia B (2020) Making society climate resilient: International progress under the Global Framework for Climate Services. Bull Amer Meteor Soc 101:E237-E252

Howlett P, Morgan MS (eds) (2011) How well do facts travel? Cambridge University Press, The dissemination of reliable knowledge

Hull DL (1975) Central subjects and historical narratives. History and Theory 14:253-274

Hyvärinen M (2016) Expectations and experientiality: Jerome Bruner's "Canonicity and Breach." Storyworlds 8(2):1-25

Intergovernmental Panel on Climate Change (IPCC) (2018) Global warming of $1.5^{\circ} \mathrm{C}$ (Masson-Delmotte V, et al., eds.). World Meteorological Organization, Geneva. https://www.ipcc.ch/sr15/. Accessed 21 Sept 2020

Jasanoff S (2010) A new climate for society. Theory Cult Soc 27:233-253

Jeffreys H (1961) The Theory of Probability, 3rd edn. Oxford University Press

Kahneman D, Tversky A (1982) Variants of uncertainty. Cognition 11:143-157

Kirchhoff CJ, Lemos MC, Dessai S (2013) Actionable knowledge for environmental decision making: Broadening the usability of climate science. Ann Rev Environ Resour 38:393-414

Kopp RE (2021) Land-grant lessons for Anthropocene universities. Clim Chang 165:28. https://doi.org/ $10.1007 / \mathrm{s} 10584-021-03029-9$

Kuhn TS (2012) The Structure of Scientific Revolutions, $50^{\text {th }}$ anniversary edn. University of Chicago Press

Lempert RJ, Schlesinger ME, Bankes SC (1996) When we don't know the costs or the benefits: Adaptive strategies for abating climate change. Clim Chang 33:235-274

Leonelli S (2016) Data-Centric Biology: A Philosophical Study. University of Chicago Press

Leonelli S, Tempini N (eds.) (2020) Data journeys in the sciences. Springer International Publishing

Lindley DV (2014) Understanding Uncertainty, revised edn. Wiley

Lloyd EA, Schweizer VJ (2014) Objectivity and a comparison of methodological scenario approaches for climate change research. Synthese 191:2049-2088

Lloyd EA, Shepherd TG (2020) Environmental catastrophes, climate change, and attribution. Ann NY Acad Sci 1469:105-124

Lloyd EA, Shepherd TG (2021) Climate change attribution and legal contexts: evidence and the role of storylines. Clim Chang 167:28. https://doi.org/10.1007/s10584-021-03177-y

Lloyd EA, Bukovsky M, Mearns LO (2021a) An analysis of the disagreement about added value by regional climate models. Synthese 198:11645-11672. https://doi.org/10.1007/s11229-020-02821-X

Lloyd EA, Lusk G, Gluck S, McGinns S (2021b) Varieties of data-centric sciences: Regional climate modeling and model organism research. Phil Sci, in press 
Løhre E, Juanchich M, Sirota M, Teigen KH, Shepherd TG (2019) Climate scientists' wide prediction intervals may be more likely but are perceived to be less certain. Wea Clim Soc 11:565-575

Lubchenco J (1998) Entering the century of the environment: A new social contract for science. Science 279:491-497

Meinke H, Nelson R, Kokic P, Stone R, Selvaraju R, Baethgen W (2006) Actionable climate knowledge: from analysis to synthesis. Clim Res 33:101-110

Merrie A, Keys P, Metian M, Österblom H (2018) Radical ocean futures-scenario development using science fiction prototyping. Futures 95:22-32

National Research Council (NRC) (1979) Carbon Dioxide and Climate: A Scientific Assessment (Charney JG, et al.). Washington, DC: The National Academies Press (https://doi.org/10.17226/12181)

Nissan H, Goddard L, Coughlan de Perez E, Furlow J, Baethgen W, Thomson MC, Mason SJ (2019) On the use and misuse of climate change projections in international development. WIREs Clim Chang 10:e579

Otto SP, Rosales A (2020) Theory in service of narratives in evolution and ecology. Amer Naturalist 195:290-299

Overeem I, Anderson RS, Wobus CW, Clow GD, Urban FE, Matell N (2011) Sea ice loss enhances wave action at the Arctic coast. Geophys Res Lett 38:L17503

Pisaric MFJ, Thienpont JR, Kokelj SV, Nesbitt H, Lantz TC, Solomon S, Smol JP (2011) Impacts of a recent storm surge on an Arctic delta ecosystem examined in the context of the last millennium. Proc Natl Acad Sci USA 108:8960-8965

Rosales A (2017) Theories that narrate the world: Ronald A. Fisher's mass selection and Sewall Wright's shifting balance. Stud Hist Phil Sci 62:22-30

Rounsevell MDA, Metzger MJ (2010) Developing qualitative scenario storylines for environmental change assessment. WIRE Clim Chang 1:606-619

Rudiak-Gould P (2013) 'We have seen it with our own eyes': Why we disagree about climate change visibility. Wea Clim Soc 5:120-132

Shepherd TG, Boyd E, Calel RA, Chapman SC, Dessai S, Dima-West IM, Fowler HJ, James R, Maraun D, Martius O, Senior CA, Sobel AH, Stainforth DA, Tett SFB, Trenberth KE, van den Hurk BJJM, Watkins NW, Wilby RL, Zenghelis DA (2018) Storylines: an alternative approach to representing uncertainty in physical aspects of climate change. Clim Chang 151:555-571

Shepherd TG (2019) Storyline approach to the construction of regional climate change information. Proc R Soc A 475:20190013

Shepherd TG (2021) Bringing physical reasoning into statistical practice in climate-change science. Clim Chang 169:2. https://doi.org/10.1007/s10584-021-03226-6

Shepherd TG, Sobel AH (2020) Localness in climate change. Comp Stud South Asia Africa \& Middle East 40:7-16

Sobel AH (2021) Usable climate science is adaptation science. Clim Chang 166:8. https://doi.org/10.1007/ s10584-021-03108-X

Star SL, Griesemer JR (1989) Institutional ecology, 'translations' and boundary objects: Amateurs and professionals in Berkeley's Museum of Vertebrate Zoology, 1907-39. Soc Stud Sci 19:387-420

Stirling A (2010) Keep it complex. Nature 468:1029-1031

Stott PA, Stone DA, Allen MR (2004) Human contribution to the European heatwave of 2003. Nature 432:610-614

Sutherland S (2013) Irrationality (first published 1992). Pinter and Martin Ltd

van Oldenborgh GJ, van der Wiel K, Kew S, Philip S, Otto F, Vautard R, King A, Lott F, Arrighi J, Singh R, van Aalst M (2021) Pathways and pitfalls in extreme event attribution. Clim Chang 166:13. https://doi. org/10.1007/s10584-021-03071-7

White $\mathrm{H}$ (1980) The value of narrativity in the representation of reality. Crit Inq 7(1):5-27

Woodward J (2003) Making Things Happen: A Theory of Causal Explanation. Oxford University Press

Wyborn C, Davila F, Pereira L, Lim M, Alvarez I, Henderson G, Luers A, Martinez Harms MJ, Maze K, Montana J, Ryan M, Sandbrook C, Shaw R, Woods E (2020) Imagining Transformative Biodiversity Futures. Nat Sustain 3:670-672

Young HR, Shepherd TG, Acidri J, Cornforth RJ, Petty C, Seaman J, Todman LC (2021) Storylines for decision-making: Climate and food security in Namibia. Clim Dev 13:515-528

Publisher's note Springer Nature remains neutral with regard to jurisdictional claims in published maps and institutional affiliations. 